\title{
Cigarette smoking and bladder cancer: an epidemiological inquiry in West Yorkshire
}

\author{
R A CARTWRIGHT, ${ }^{1} \mathrm{R}$ ADIB, ${ }^{2}$ I APPLEYARD,$^{3} \mathrm{R}$ W GLASHAN, ${ }^{4}$ B GRAY,${ }^{5}$ P A \\ HAMILTON-STEWART, ${ }^{5}$ M ROBINSON, ${ }^{6}$ AND D BARHAM-HALL
}

From the Epidemiology Unit, ${ }^{1}$ Yorkshire Regional Cancer Organisation. Cookridge Hospital, Leeds, 'Pinderfields Hospital, ${ }^{2}$ Wakefield, Airedale Hospital, ${ }^{3}$ Keighley, Hud̄dersfield Royal Infirmary, ${ }^{4}$ Bradford Royal Infirmary, ${ }^{5}$ and Pontefract District General Hospital, ${ }^{6}$ West Yorkshire, UK

SUMMARY Results are given of a case-control study on bladder cancer in West Yorkshire. The aim of the study was to assess what risks exist for cigarette smoking in the United Kingdom and also to investigate if a dose response effect was present. The study shows for the first time in the United Kingdom a positive but weak relationship between cigarette smoking and bladder cancer. Close examination of the data with regard to this effect shows that a complex set of relationships result when the quantity smoked and the period of smoking are taken into account. A dose response effect is weakly demonstrated when a medium quantity of cigarettes are smoked but it is not present at all in those who smoked most cigarettes for the longest periods. No risk appears to exist for those who have smoked only filter cigarettes. The results are contrasted with similar studies and the significance of the observations are discussed.

An association between cigarette consumption and bladder cancer is known as a result of various types of epidemiological inquiry. Correlation studies by Lea, ${ }^{1}$ Fraumeni, ${ }^{2}$ and Stevens and Moolgavkar, ${ }^{3}$ several follow up and birth cohort studies, ${ }^{4-6}$ and some case control studies $^{7-13}$ all indicate that risks exist. There are, however, some deficiencies in our knowledge, in particular no other English case-control study has yet shown a risk. ${ }^{14}$ Part of the work presented here has already been published in a preliminary form ${ }^{15}$ but it is the purpose of this study to analyse further the relation between bladder cancer and smoking. Aspects of the relationship between smoking habits, other risk factors, and bladder cancer will be dealt with in subsequent papers.

\section{Method}

Bladder cancer was defined as any transitional cell carcinoma of the urothelium of whatever grade; the raised, well differentiated lesions, once known as papilloma, were included as part of the range of carcinomas.

A district health authority based case-control study was initiated in 1978 in six districts in West Yorkshire and an attempt was made to interview all incident cases of bladder cancer occurring from 1 October
1978 to 30 September 1981 . In addition all prevalent cases of bladder cancer were interviewed in three of the districts between 1 April and 30 September 1978. Prevalent cases were defined as those diagnosed in the previous five years. These were enumerated with the help of the cancer registry, and all those alive and who could be traced were interviewed in the study.

There were four interviewers and except for a few cases at the end of the study each interviewer interviewed a case and its matched controls. A prevalent case had one control and an incident case two. A few cases were interviewed at home towards the end of the study, but all controls were interviewed in hospital. The study resulted in interviews with 1259 cases and 1981 controls, which represents over $90 \%$ of all incident cases known to occur within the defined area during the periods in question. Roughly $50 \%$ of all known incident cases during 1973-8 were included as prevalent cases. There were 617 incident cases and the rest were prevalent in type. No age or sex bias existed in the cases who were not interviewed. The controls had an equal probability as the cases of originating anywhere within the health districts in question.

Table 1 gives the age and sex of cases and controls interviewed and table 2 shows the geographical 256 
origin of cases interviewed along with the numbers of control interviews. Controls were defined as hospital cases of the same sex and similar age ( \pm 3 years) occupying a hospital bed within three months of the case, in the same hospital as the case. The controls were selected, once a case interview had taken place, by an interviewer approaching selected hospital wards in strict rotation. All the potentially eligible controls in one ward were noted and if there was more than one patient they were approached in alphabetical order for permission to be interviewed. Normally, the first patient agreed. A note was made of the illness causing that hospital admission, but no distinction was made between new disease episodes or a prevalent condition. Illnesses were broadly divided into "smoking related" as chronic chest diseases and arterial disease and "other" which were either cold surgery and accident cases or a wide variety of ill defined geriatric admissions. The proportion of cases of each diagnosis reflect the distribution of wards visited in each hospital. About $25 \%$ of controls had arterial disease, $60 \%$ had minor surgery, accident, or cold surgery, $10 \%$ had chronic chest conditions, and the rest a wide range of other conditions covering all systems with the exception of other malignant disease relating to current admission. Patients with whom the interviewer could not communicate or where there was doubt about the ability of the interviewee to recall accurately details of past events, were also omitted. In Bradford 107 neighbourhood controls were interviewed who were matched for age and sex of cases and chosen by a random method from among the case's general practitioner lists. These 107 neighbourhood controls were contrasted with their hospital controls and no differences found between them in smoking habits. The cases were then pooled with the rest of the controls for further analysis.

The smoking information of controls was matched with the data acquired from the paired case. For controls of incident cases smoking data up to the point of interview were taken while for controls of prevalent cases the date of the case diagnosis was taken as a cut off point for smoking (and other)

Table 1 Number of cases and controls interviewed by age at diagnosis of case and control for disease of admission

\begin{tabular}{llccl}
\hline Age groups & $\begin{array}{l}\text { Male } \\
\text { cases }\end{array}$ & $\begin{array}{l}\text { Male } \\
\text { controls }\end{array}$ & $\begin{array}{l}\text { Female } \\
\text { cases }\end{array}$ & $\begin{array}{l}\text { Female } \\
\text { controls }\end{array}$ \\
\hline$<60$ & 354 & 426 & 108 & 173 \\
$60-9$ & 323 & 515 & 97 & 183 \\
$>69$ & 255 & 461 & 122 & 223 \\
Totals & 932 & 1402 & 327 & 579 \\
\hline
\end{tabular}

Table 2 Number of cases and controls interviewed by health districts

\begin{tabular}{lcc}
\hline District & $\begin{array}{l}\text { Cases } \\
\text { interviewed }\end{array}$ & $\begin{array}{l}\text { Controls } \\
\text { interviewed }\end{array}$ \\
\hline Airedale (Keighley) & 26 & 52 \\
Bradford & 554 & $846 \dagger$ \\
Calderdale (Halifax) & 70 & 140 \\
Huddersfield & 378 & 566 \\
Pontefract & 48 & 95 \\
Wakefield & 189 & 282 \\
Total & 1259 & 1981 \\
\hline
\end{tabular}

-Number of controls varies due to variable matching ratio between incident and prevalent cases.

tFirst 107 Bradford prevalent cases also had a neighbourhood control.

information about the control. This was true even if the control was younger than the case because the mean age of controls and cases is identical, although the position of the stratification bands mean that there are some slight excesses or deficits in some age subgroups.

The information used in this paper relating to smoking habits resulted from direct questioning by trained interviewers. A smoker was defined arbitrarily as anyone who had smoked at least 1000 cigarettes on a regular basis for any length of time. Those who had smoked less than this were classed as never smokers. Information about filter and plain was gained independently; the manufactured cigarettes were pooled with those self rolled. Filter cigarettes have been generally available since 1929 . A few people had used filter holders before that date, others had introduced filters into hand rolled cigarettes, and both subgroups have been pooled with the user of manufactured filter cigarettes. Hand made cigarettes were counted on the basis of the tobacco purchased a week using a formula of Doll and Hill of $1 \mathrm{oz}$ being equivalent to 26.5 cigarettes. $^{16}$

Interviews were constantly monitored to ensure consistency between interviewers. Information such as age and date of onset of first symptoms was checked from the hospital notes in relation to the statements made by cases and controls.

The information was coded and analysed with the help of the Leeds University Amdahl computer and the Statistical Package for the Social Sciences. Risk ratios were computed after Mantel and Haenszell ${ }^{17}$ with confidence limits by Miettinen ${ }^{18}$ or a trend test was used.$^{19}$ The analyses were based on the principles of grouped data outlined by Breslow and Day's and were undertaken using the programs of Rothman and Boice. ${ }^{21}$

The grouped data were subdivided by age $(<60$, $60-69,>69)$ and sex, account being taken of these factors in all the calculations presented: the results without significant heterogeneity for these factors 
were expressed as summary statistics. The attributable risk percentages were computed after Cole and MacMahon. ${ }^{22}$

\section{Results}

Tables 1 and 2 show the number of cases and controls in the analyses and their place of interview. Some of the later present fewer results than shown here due to lack of certain information.

Table 3 gives the overall result of "ever" versus "never" cigarette smokers from the entire series. These results are similar to those reported in a preliminary study ${ }^{15}$ for men and indicate a significant risk for men but a lower and barely significant risk for women. We propose to analyse this relationship further. The contrast between ever and never smokers may be inappropriate and this is investigated in table 4. Here never smokers and those few individuals (five cases) who had given up smoking for more than 35 years were grouped and contrasted with those who had ceased smoking for intermediate periods and current smokers. Current smokers were defined to include those smoking at the time of diagnosis and those who stopped up to five years before diagnosis, because it was thought that those who had recently given up smoking might not truly have done so or might have done so for reasons connected with the disease and so could not properly be distinguished from current smokers in a manner analogous to those who had given up smoking for longer periiods. In this table never smokers and those given up for a considerable period was used as a standard, while account was taken of the age subdivisions. The heterogeneity results show that no significant differences occur between age groups.

Table 4 indicates that for men the risks from cigarette smoking decline after abstinence of at least five years; the resulting risk for current smokers

Table 3 Risks for cigarette smoking and bladder cancer: ever smokers versus never smokers accounting for age

\begin{tabular}{|c|c|c|c|c|}
\hline & $\begin{array}{l}\text { No of } \\
\text { cases }\end{array}$ & $\begin{array}{l}\text { No of } \\
\text { controls }\end{array}$ & $\begin{array}{l}\text { Risk ratio } \\
\text { (maximum } \\
\text { likelihood) }\end{array}$ & $\begin{array}{l}95 \% \\
\text { Confidence } \\
\text { limits }\end{array}$ \\
\hline $\begin{array}{l}\text { Men: } \\
\text { Ever smokers } \\
\text { Never smokers }\end{array}$ & $\begin{array}{c}840 \\
92 \\
92 \\
\mathrm{Chi}^{(\mathrm{M}} \\
\mathrm{Chi}^{2}(\mathrm{H}\end{array}$ & $\begin{aligned} & 1245 \\
& 212 \\
= & 3.34 \\
= & 0.852,\end{aligned}$ & $\begin{array}{l}1.56 \\
1.00 \\
0.001 \\
p=0.65\end{array}$ & $\begin{array}{l}1.20-2.02 \\
-\end{array}$ \\
\hline $\begin{array}{l}\text { Women: } \\
\text { Ever smokers } \\
\text { Never smokers }\end{array}$ & $\begin{array}{l}150 \\
177 \\
\text { Chi (M } \\
\text { Chi }^{2}(1\end{array}$ & $\begin{array}{c}211 \\
313 \\
1 \cdot 37 \mathrm{p} \\
0 \cdot 253\end{array}$ & $\begin{array}{c}1.22 \\
1.00 \\
.50 \\
p=0.88\end{array}$ & $\begin{array}{l}0.92-1.64 \\
-\end{array}$ \\
\hline
\end{tabular}

M-H $=$ Mantel-Haenszel

HET $=$ Heterogeneity .
Table 4 Risks relating to the effect of giving up smoking when never smokers and those given up for over 35 years are contrasted with other groups, and accounting for age using the Mantel extension test for trend

\begin{tabular}{|c|c|c|c|c|c|c|}
\hline $\begin{array}{l}\text { No of } \\
\text { years ceased }\end{array}$ & $\begin{array}{l}\text { Male } \\
\text { cases }\end{array}$ & Controls & $\boldsymbol{R} R$ & $\begin{array}{l}\text { Female } \\
\text { cases }\end{array}$ & Controls & $R R$ \\
\hline $\begin{array}{l}\text { Current and } \\
\text { under } 5 \text { years }\end{array}$ & 635 & 823 & 1.65 & 135 & 169 & 1.40 \\
\hline $6-15$ & 80 & 176 & 1.03 & 6 & 18 & 0.46 \\
\hline $\begin{array}{l}16-25 \\
26-35\end{array}$ & 33 & $\begin{array}{l}79 \\
57\end{array}$ & $\begin{array}{l}1 \cdot 12 \\
0.92\end{array}$ & 4 & 15 & 0.49 \\
\hline \multirow[t]{2}{*}{$\begin{array}{l}\text { Never or over } \\
35 \text { years }\end{array}$} & 103 & 223 & $1 \cdot 00$ & 175 & 294 & $1 \cdot 00$ \\
\hline & \multicolumn{3}{|c|}{$\begin{array}{l}\text { Chi }(\mathrm{MH})=4.56 \\
p=<0.001 \\
\text { Chi }(\mathrm{HET})^{*}=0.225,3 \mathrm{df} \dagger \\
p=0.97\end{array}$} & \multicolumn{3}{|c|}{$\begin{array}{l}\text { Chi }(\mathrm{MH})=2.08 \\
p=0.02 \\
\text { Chi }(\text { HET })^{*}=0.748,2 \mathrm{df} \dagger \\
p=0.69\end{array}$} \\
\hline
\end{tabular}

$\mathbf{R R}=$ Risk ratio.

$\mathrm{M}-\mathrm{H}=$ Mantel-Haenszel.

"Chi squared value for heterogeneity.

†Number of degrees of freedom vary because the age groups $16-25$ and 26-35 are pooled for women but not for men.

being somewhat higher than that in table 3 . The same is broadly true of women, although the subsample sizes become very small. Nevertheless, the resulting risk for women is now statistically significant when contrasted with the other subgroups. The attributable risk percentage for men and women of the redefined current smoker is 30 and 12 respectively.

For this reason, whenever possible, the rest of the analyses contrast current and recently given up smokers with those who had never smoked or given up for at least five years. This latter group is now called "non-smokers." Again, little heterogeneity exists between the sexes, although the overall magnitude of the risk for women is less than that for men.

Table 5 shows that the risk of the current smokers varies slightly with age at diagnosis but not to any significant degree.

Table 6 investigates the relationship between the type of cigarette smoked and risks by age with summary results, accounting for both age and sex. These results contrast never smokers with all other groups. The groups used are those who smoked only plain-that is, non-filter-cigarettes, filter cigarettes, and those who have used both, with at least five years' experience of both sorts. Hand rolled cigarettes are placed into the appropriate subgroup. Only one age group showed sex differences: the 60-69 group for plain cigarette users and these results are given for both sexes. The other results are all statistically homogeneous between the sexes. The summary 
Table 5 Effect of age at diagnosis on risks of smoking in bladder cancer: current smokers contrasted with nonsmokers, accounting for sex at each age group

\begin{tabular}{|c|c|c|c|c|c|c|}
\hline Age groups & $\begin{array}{l}\text { Maximum } \\
\text { likelihood } \\
\text { risk ratio }\end{array}$ & $\begin{array}{l}95 \% \\
\text { Confidence } \\
\text { limits }\end{array}$ & $\begin{array}{l}\text { Chi } \\
\text { Mantel- } \\
\text { Haenszel }\end{array}$ & $p$ & $\begin{array}{l}C h i^{2} \\
H E T\end{array}$ & $p$ \\
\hline$<60$ & 1.68 & $1 \cdot 29-2 \cdot 19$ & 3.84 & $<0.0001$ & 1.06 & 0.59 \\
\hline $60-69$ & 1.56 & $1 \cdot 20-2 \cdot 02$ & 3.34 & $<0.0001$ & 0.44 & 0.80 \\
\hline$>70$ & 1.46 & $1 \cdot 12-1 \cdot 91$ & 2.77 & 0.003 & 0.05 & 0.98 \\
\hline
\end{tabular}

HET $=$ Heterogeneity.

results show that no significant age differences occur and that both plain cigarette smokers and mixed smokers have significant risks. No risks are observed in those 58 cases who smoke only filter cigarettes.

Table 7 examines the relationship between the mean quantity of cigarettes smoked a day and risks of bladder cancer when age is accounted for: current smokers are contrasted with the rest. No major sex differences are seen here. The quantity smoked, given in units of 10 , is computed on the basis of the averaged life times history of cigarettes smoked. Non-smokers are contrasted with current and recently given up smokers. The internal heterogeneity is not statistically significantly high, while the Mantel-Haenszel chi is highly significant for the risks. The results show the lowest risk is for those who smoke the most and the highest risks are for intermediate smokers.

The relationship between duration of the cigarette smoking histories of current versus non-smokers for both sexes separately are summarised in table 8 and account for age. They indicate low risk values for those who have smoked 36-45 years and higher values for greater and fewer years. The two smallest groups who smoked between six and 15 years and 16 and 25 years also have high risks. All these results are internally homogeneous.

Table 9 pools much of the available data to examine the relationship between length of time smoked and the number of cigarettes consumed. The risk ratios only are presented. Never smokers and those who smoked less than five years were used as a contrast. The results indicate that the risks increase according to the different length of time smoked but in no clear ordinal sequence. With light smokers

Table 6 Effect of age on overall risk by type of cigarette smoked, accounting for sex and contrasting never smokers with other groups

\begin{tabular}{|c|c|c|c|c|c|c|c|}
\hline Age groups & $\begin{array}{l}\text { No of } \\
\text { smokers }\end{array}$ & $\begin{array}{l}\text { Maximum } \\
\text { likelihood } \\
\text { risk ratio }\end{array}$ & $\begin{array}{l}95 \% \\
\text { Confidence } \\
\text { limits }\end{array}$ & $\begin{array}{l}\text { Mantel- } \\
\text { Haenszel } \\
\text { Chi }\end{array}$ & $p$ & $\begin{array}{l}C h i^{2} \\
(H E T)\end{array}$ & $p$ \\
\hline \multicolumn{8}{|c|}{ Only smoked plain cigarettes } \\
\hline$<60$ & 164 & $1 \cdot 23$ & $0 \cdot 85-1.79$ & 1.079 & $0 \cdot 14$ & $1 \cdot 087$ & 0.30 \\
\hline $60-69\}$ & $\begin{array}{r}169 \\
5\end{array}$ & $\begin{array}{l}1.98(\mathrm{M}) \\
0.59(\mathrm{~F})\end{array}$ & $\begin{array}{l}1 \cdot 20-3 \cdot 28 \\
0 \cdot 20-1 \cdot 71\end{array}$ & $\begin{array}{r}2.651 \\
-0.973\end{array}$ & $\begin{array}{l}0.004 \\
0.17\end{array}$ & $\begin{array}{l}- \\
-\end{array}$ & - \\
\hline $\begin{array}{l}>69 \\
0.30\end{array}$ & 140 & $1 \cdot 37$ & $0 \cdot 87-2 \cdot 18$ & $1 \cdot 344$ & 0.09 & 1.075 & 0.30 \\
\hline Summaryt & & $1 \cdot 36$ & $1 \cdot 07-1 \cdot 73$ & $2 \cdot 500$ & 0.006 & $6 \cdot 880$ & 0.23 \\
\hline \multicolumn{8}{|c|}{ Only smoked filter cigaretes } \\
\hline$<60$ & 28 & 0.90 & $0.53-1.53$ & -0.389 & $0 \cdot 35$ & 0.041 & 0.84 \\
\hline $60-69$ & 16 & $1 \cdot 32$ & $0.67-2.63$ & 0.798 & $0 \cdot 21$ & 0.035 & $0 \cdot 85$ \\
\hline$>69$ & 14 & 1.09 & $0 \cdot 54-2 \cdot 19$ & $0 \cdot 239$ & $0 \cdot 19$ & $0 \cdot 186$ & 0.67 \\
\hline Summary & & $1 \cdot 05$ & $0 \cdot 73-1 \cdot 51$ & 0.267 & 0.37 & 1.037 & 0.96 \\
\hline \multicolumn{8}{|c|}{ Smoked both plain and filter cigarettes } \\
\hline$<60$ & 180 & $1 \cdot 37$ & $0.97-1.95$ & 1.772 & 0.04 & $<0.001$ & 0.99 \\
\hline $60-69$ & 161 & 1.68 & $1 \cdot 15-2 \cdot 45$ & $2 \cdot 658$ & 0.004 & 0.081 & 0.78 \\
\hline$>69$ & 110 & $1 \cdot 80$ & $1.21-2.69$ & $2 \cdot 893$ & 0.002 & 0.214 & 0.64 \\
\hline Summary ${ }^{\dagger}$ & & $1 \cdot 59$ & $1 \cdot 28-1 \cdot 97$ & $4 \cdot 117$ & $<0.001$ & 1.420 & 0.92 \\
\hline
\end{tabular}

*Heterogeneity between sexes. †Accounting for both sex and age. 
Table 7 Quantities of ciagarettes consumed by current smokers contrasted with non-smokers: accounting for age and giving the Mantel extension for trend test statistics and summary risks accounting for age and sex

\begin{tabular}{|c|c|c|c|c|}
\hline & \multirow[t]{2}{*}{ Non-smokers } & \multicolumn{3}{|c|}{ Current smokers and recently ceased } \\
\hline & & $<10 /$ day & 10-20/day & $>20 /$ day \\
\hline \multicolumn{5}{|l|}{ Men: } \\
\hline Cases & 264 & 95 & 424 & 146 \\
\hline Controls & 566 & 134 & 514 & 230 \\
\hline \multirow[t]{2}{*}{ Risk ratio } & 1.00 & 1.52 & 1.72 & $1 \cdot 26$ \\
\hline & \multicolumn{4}{|c|}{$\operatorname{Chi}(\mathrm{M}-\mathrm{H})=3.98 \mathrm{p}=0.001 \mathrm{Ch}$} \\
\hline \multicolumn{5}{|l|}{ Women: } \\
\hline Cases & 187 & 37 & 100 & 3 \\
\hline Controls & 351 & 42 & 116 & 16 \\
\hline \multirow[t]{2}{*}{ Risk ratio } & 1.00 & 1.60 & 1.63 & $1.09^{*}$ \\
\hline & \multicolumn{4}{|c|}{ Chi $(M-H)=1.92 p=0.003 \mathrm{Ch}$} \\
\hline \multicolumn{2}{|c|}{ Summary risks $\mathbf{1 . 0 0}$} & 1.55 & 1.68 & $1 \cdot 19$ \\
\hline
\end{tabular}

M-H = Mantel-Haenszel.

HET $=$ Heterogeneity.

*This risk is apparently anomalous due to the grouped number of cases and controls presented in this table but is accounted for by the numbers in different age strata.

$(<10 /$ day) the risks could increase after 26 years and with medium smokers (10-20/day) after 16 years for women only. With heavy smokers ( $>20 /$ day) the trend results are non-significant.

The greatest inconsistency in these data lie in the group who have smoked the greatest quantity for the longest period. This group has little risk of bladder cancer.

\section{Disussion}

This paper deals with the complex weak relationships that seem to exist between smoking and bladder cancer. Before commenting on this some general points about the study need to be discussed.
This study includes both prevalent and incident cases. All preliminary analyses took this aspect into consideration. There were some important differences between the type of case but none in the aspects reported in this paper. For the purpose of the present analysis the two types of case were pooled before being grouped into the appropriate strata for analysis.

As this case-control study made various attempts to avoid bias, these results are not presented in detail here. They include the use of a series of interviews whose results were contrasted. The results indicate that no appreciable interviewer bias appeared to exist. The reinterviewing of a small proportion of cases, some years apart, took place. Recall difficulties were trivial when tested in this way but it was thought that the major distortions of memory relating to cigarette consumption had already taken place by the time of the interview and would be impossible to cross check. As differential recall bias between cases and controls seemed unlikely to occur, this was not checked, although the vast majority of interviews took place in a similar hospital environment.

Possibly the hospital controls have an intrinsically different smoking experience than the rest of the general population. This is thought to be unlikely for two reasons; a small population based control series was extracted for Bradford and the smoking histories proved to be the same within statistical limits as Bradford hospital controls. In addition the reasons for admission to hospital of the hospital controls were perused and those with the non-malignant "smoking related illnesses" (arterial disease and chronic chest diseases in the main) were contrasted with the rest. No statistically significant differences in smoking habits were shown, although there was a slight excess use of cigarettes in the smoking related illness group. In the light of this it was thought justified to use the

Table 8 Period smoked by current smokers contrasted with non-smokers and accounting for age with summary risks accounting for age and sexes

\begin{tabular}{|c|c|c|c|c|c|c|}
\hline & \multicolumn{6}{|l|}{ Summary risk ratios } \\
\hline & \multirow[t]{2}{*}{ Non-smokers } & \multicolumn{5}{|c|}{ Current smokers: years smoked } \\
\hline & & $6-15$ & $16-25$ & $26-35$ & $36-45$ & $>45$ \\
\hline \multicolumn{7}{|l|}{ Men: } \\
\hline Cases & 264 & 15 & 52 & 122 & 200 & 176 \\
\hline Controls & 566 & 18 & 57 & 163 & 169 & 371 \\
\hline \multirow[t]{2}{*}{ Risk ratio } & 1.00 & $1 \cdot 71$ & $1 \cdot 70$ & 1.09 & $1 \cdot 35$ & 1.44 \\
\hline & Chi $(M-H)=4.83$ & $p=<0.001$ & $1 \mathrm{Chi}^{2}(\mathrm{HET})=0 \cdot 342$ & $p=0.843$ & & \\
\hline \multicolumn{7}{|l|}{ Women: } \\
\hline Cases & 187 & 18 & 20 & 32 & 41 & 29 \\
\hline Controls & 351 & 12 & 24 & 42 & 60 & 35 \\
\hline \multirow{2}{*}{ Risk ratio } & 1.00 & 2.55 & 1.76 & $1 \cdot 71$ & $1 \cdot 17$ & 1.59 \\
\hline & Chi $(M-H)=1.97$ & $p=0.02$ & $\operatorname{Chi}^{2}($ HET $)=0.538 \mathrm{p}$ & $=0.764$ & & \\
\hline
\end{tabular}

MH = Mantel-Haenszel.

HET $=$ Heterogeneity. 
Table 9 Risks associated with period smoked and average number of cigarettes consumed; all smokers contrasted with never smokers by the Mantel test for trend accounting for age

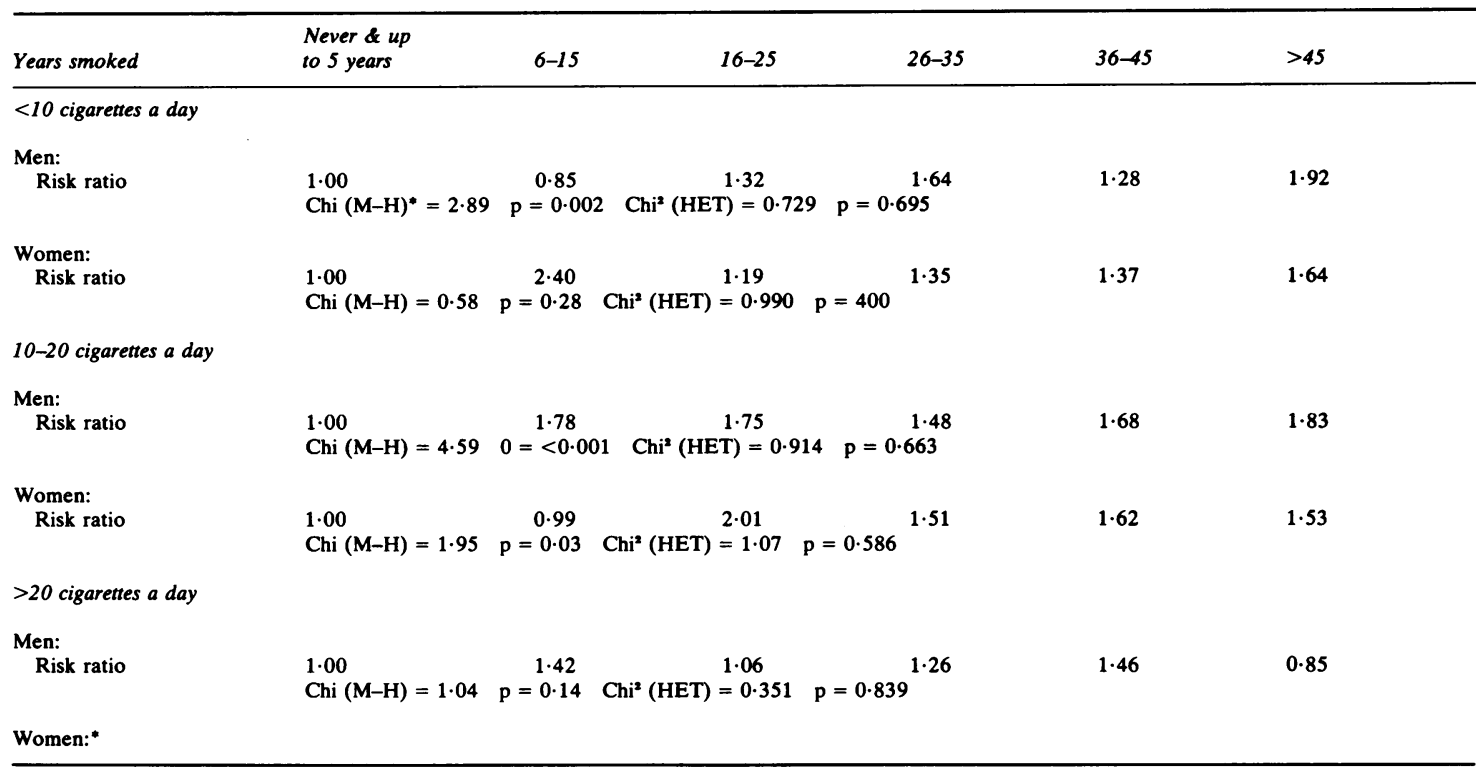

MH = Mantel-Haenszel.

HET = Heterogeneity.

* Not enough variation or numbers.

entire set of hospital based controls as the comparison group.

The overall risks for cigarette smoking and bladder cancer are given as 1.6 for men and 1.3 for women, ever smokers versus never smokers, but these results are heterogeneous and various questions arise, in particular whether or not to include past smokers. Table 4 gives the answer to this, and when non-smokers are redefined the resultant overall risks become 1.7 for men and 1.4 for women, with confidence limits of $1 \cdot 4-2 \cdot 1$ and $1 \cdot 1-1 \cdot 9$.

The magnitude of the female risk is lower than that of the preliminary study while the men's result is similar to this earlier report. ${ }^{15}$

In general these risks are similar to or lower than other case-control design studies that have results in the range $1 \cdot 4,{ }^{16} 1 \cdot 9,{ }^{8}$ and $1 \cdot 89^{23}$ for men, $1 \cdot 2,{ }^{10}$ and $2 \cdot 0^{9}$ for women, and $1.7^{13}$ for both sexes. Other studies have reported higher risk ratios but often because the comparisons were dissimilar. ${ }^{11}$ Anthony and Thomas report the only British study which had addressed this question and they found no risk for cigarette smoking in bladder cancer. ${ }^{14}$ That study, however, used retrospectively assigned controls for a subset of the original cases. The cases from their study came from an area of Yorkshire not covered by the present study.
The attributable risk for all current smokers amounts to $30 \%$ for men and $12 \%$ for women. The role of cigarette smoking in this Yorkshire series is, therefore, quite small with regard to the totality of causes of bladder cancer. It is not surprising, however, that a risk should exist in the United Kingdom, in common with North America and other parts of the world. Various suggestions have been made as to why this relationship might exist. Animal work indicates a causal association. The urine of cigarette smokers is mutagenic ${ }^{24}$ and it had earlier been suggested that the quantities of 2-naphthylamine found in cigarette smoke might be responsible for the bladder tumour. ${ }^{25}$ Many carcinogenic substances, however, including many aromatic amines and nitrosamines are found in cigarette smoke. ${ }^{28}$

Furthermore, the type of cigarette smoked appears to be important in that those who have exclusively smoked filter cigarettes have no risk. This is supported by Vineis et al. ${ }^{27}$ The greatest risk is in those who have smoked both plain and filter-possibly due to the length of time smoked rather than an effect between the types of cigarette.

The group who have only ever smoked filter cigarettes are probably quite unusual; they were a distinct minority of smokers from the time when such 
cigarettes became available in 1929 until the 1950s. In addition some early filters were made of asbestos, and Clemmesen (personal communication) has suggested that this group might show no risks because they are a survivor group; the majority having died of lung cancer. In any event they are a small group when compared with the other categories.

Table 7 indicates that the risks for bladder cancer for heavy smokers are less than the risk for moderate smokers. This is similar to the results of Cole et al ${ }^{9}$ for men who recorded a risk of $\mathbf{1 . 8 3}$ for those smoking over two and a half packets a day contrasted with a risk of $2 \cdot 17$ for smokers of one and a half to two and a half packets a day, although statistical differences between these results are unlikely. This phenomenon has also been observed by Vineis (personal communication) in Italian smokers of blond cigarettes. Wynder and Goldsmith, however, found no such relationship and those who smoked heaviest had the highest risk for both men and women, ${ }^{8}$ and this is the experience of Vineis et al who found very high risks for those who smoked the greatest quantity;27 although this is largely in smokers of black tobacco.

The low results for the greatest exposure could be due to a poor quality of control selection; hospital inmates being a group known to smoke more than the public as a whole. It has been argued earlier that this is not a major effect. There may still be hidden biases, however, in the selection of hospital controls, despite the fact that the small group of population controls were similar in every respect to their local hospital controls.

If the lowered risks are a real effect among cases it could be that this is the long term outcome of competitive diseases related to tobacco consumption: leaving a very resistant group behind. At least in the United Kingdom the real realtionships lie with moderate smokers. This effect is also seen in table 9 in the group which has been smoking for the longest time using the greatest number of cigarettes.

English experience might also differ from that in the United States with respect to age at onset, as shown in table 5. Younger ages at onset have higher risks in Italy. ${ }^{27}$ Cole showed an excess risk for younger cases and postulated a cohort effect. ${ }^{9}$ This British series shows a slightly higher risk for the younger cases, although there are no significant differences between the age groups. In addition type of tobacco may well be important. Vineis (personal communication) has suggested that black tobacco gives a considerably greater risk than blond tobacco when related to the aetiology of Italian bladder tumours. The type of curing for cigarette tobacco should be further investigated with respect to general cancer risks.

Table 8 evaluates the total duration of smoking histories. Current smokers are grouped into decades. Here the inconsistent results could be due to the relatively small numbers in the groups that have smoked for under 25 years. Alternatively, the "excess" of cases seen in those cells with lower risks could be due to susceptible people or those engaged in a life style that puts them at further risk of bladder cancer. This aspect will be explored in studies of other risk factors, but the concept has some broad support from work on $\mathrm{N}$-acetyltransferase variations. ${ }^{28}$

Table 9 combines both the number of years and the quantity smoked. These results indicate a rough dose response for light smokers but most of the results do not show a clear increase in risk with increased dose. The heavy smoking group gives non-significantly different results but a slight excess of cases after six years of cigarette smoking is indicated.

Overall, these results indicate that the accepted relationship between cigarette smoking and bladder cancer is quite a complex one and in the United Kingdon amounts to under one third of the attributable risk for bladder cancer. Although we have not studied many aspects of smoking, the evidence is that cigarette smoking has several, possibly independent, parts to play in bladder carcinogenesis, some initiating and other promotional. This may be related to the numerous noxious substances present in cigarette smoke.

In addition major differences between some North American and Italian work and the results presented here suggest that international variations occur. This aspect needs further study but could be due to different methods of control selection, different national smoking patterns, different curing methods in the production of cigarettes or other local causes of bladder cancer. More work is in progress to define further risks in bladder cancer with respect to other aspects of smoking, such as inhalation and other tobacco products.

This work was supported by a Medical Research Council project grant. We would particularly like to thank Mr McAlister for his support before his retiřement. In addition numerous consultants have helped us by allowing their patients to be interviewed as control subjects. We are most grateful to them and their junior staffs as well as many members of the nursing profession for allowing us access to wards and clinics throughout the four years of this study. Jack Cuzick helped us with the statistical analysis. 
We would also like to thank Fiona Landells for typing the drafts of this paper. Finally, Trevor Dale, Pat Brown, Jan Parker, and one of us (Denise Barham-Hall) interviewed the cases.

\section{References}

${ }^{1}$ Lea AJ. Cigarette smoking and cancer of the lungs and bladder. Lancet 1966; i: 590-1.

${ }^{2}$ Fraumeni JF. Cigarette smoking and cancers of the urinary tract: geographic variation in the United States. J Natl Cancer Inst 1968; 41: 1205-11.

${ }^{3}$ Stevens RG, Moolgavkar SH. Estimation of relative risk from vital data: smoking and cancers of the lung and bladder. J. Natl Cancer Inst 1979; 63: 1357-7.

${ }^{4}$ Armstrong B, Doll R. Bladder cancer mortality in England and Wales in relation to cigarette smoking and saccharin consumption. Br J Prev Soc Med 1974; 28: 233-40.

${ }^{5}$ Khan HA. The Dorn study of smoking and mortality among United States veterans. Natl Cancer Inst Monogr 1960; 19: 1-125.

${ }^{6} \mathrm{Hammond}$ EC. Smoking in relation to death rates of one million men and women. Natl Cancer Inst Monogr 1966; 19: $122-204$.

${ }^{7}$ Lilienfeld AM, Levin ML, Moore GE. The association of smoking with cancer of the urinary bladder in humans. Arch Intern Med 1956; 98: 129-35.

${ }^{8}$ Wynder EL, Goldsmith R. The epidemiology of bladder cancer-a second look. Cancer 1977: 40: 1246-68.

${ }^{9}$ Cole P, Monson RR, Hanning H, Friedell GH. Smoking and cancer of the lower urinary tract. $N$ Engl $J$ Med 1971; 284: 129-34.

${ }^{10}$ Dunham LJ, Robson AS, Stewart HL, et al. Rates, interview and pathology study of cancer of the urinary bladder in New Orleans, Louisiana. J Natl Cancer Inst 1968; 41: 683-701.

${ }^{11}$ Morgan RW, Jain MG. Bladder cancer-smoking, beverages and artificial sweeteners. Can Med Ass J 1974; 111: 1067-70.

${ }^{12}$ Miller AB. The etiology of bladder cancer from the epidemiological viewpoint. Cancer Res 1977; 37: 2939-42.
${ }^{13}$ Miller CT, Neutel CI, Nair RC, Marrett LD, Last JM, Collins WE. Relative importance of risk factors in bladder carcinogenesis. J Chronic Dis 1978; 31: 51-6.

${ }^{14}$ Anthony HM, Thomas GM. Bladder tumours and smoking. Int J Cancer 1970; 5: 266-72.

${ }^{15}$ Cartwright RA, Adib R, Glashan RW, Gray BK. The epidemiology of bladder cancer in West Yorkshire. A preliminary report on non-occupational aetiologies. Carcinogenesis 1981; 2: 343-7.

${ }^{16}$ Doll R, Hill AB. A study of the aetiology of lung cancer. Br Med J 1952; ii: 1271-86.

${ }^{17}$ Mantel N, Haenszel W. Statistical aspects of the analysis of data from retrospective studies of disease. JNCI 1959; 22: 719-48.

${ }^{18}$ Miettinen OS. Estimability and estimation in case-referent studies. Am J Epidemiol 1976; 102: 235-66.

${ }^{19}$ Mantel N. Chi squared tests with one degree of freedom: extension of the Mantel-Haenszel procedure. Journal of the American Statistical Association 1963; 59: 690-700.

${ }^{20}$ Breslow NE, Day NE. Statistical methods of cancer research. Vol 1. Lyon: International Agency for Research on Cancer, 1980.

${ }^{21}$ Rothman KJ, Boice JD. Epidemiological analysis with a programmable calculator. Washington: US Department of Health, NIH, 1979.

${ }^{22}$ Cole $\mathrm{P}$, MacMahon B. Attributable risk percent in case control studies. Br J Prev Soc Med 1971; 25: 242-4.

${ }^{23}$ Mommsen S, Aagaard J, Sell A. An epidemiological case-control study of bladder cancer in males from a predominantly rural district. Eur $J$ Cancer (in press).

${ }^{24}$ Yamasaki E, Ames BN. Concentration of mutagens fron urine by absorption with nonpolar resin XAD-2: cigarette smokers have mutagenic urine. Proc Natl Acad Sci, USA 1977; 74: 3555-9.

${ }^{25}$ Hoffman D, Masuda Y, Wynder EL. Alpha naphthylamine and beta naphthylamine in cigarette smoke. Nature 1969; 221: 254-6.

${ }^{26}$ Hecht SS, Tso TC, Hoffman D. Selective reduction of tumourigenicity of tobacco smoke. Proceedings of the III world conference on smoking and health. Washington: Department of Health Education, and Welfare, 1976: 535-45.

${ }^{27}$ Vineis P, Frea B, Uberti E, Ghisetti V, Terracini B. Bladder cancer and cigarette smoking in males: a case-control study. Tumori 1983; 69: 17-22.

${ }^{28}$ Cartwright RA, Glashan RW, Rogers HD, et al. The role of $\mathrm{N}$-acetyltransferase phenotypes in bladder carcinogenesis: a pharmaco-genetic epidemiological approach to bladder cancer. Lancet 1982; ii: 842-6. 